\title{
The illusion of "The Garden" A reflection on the works and ideas of the painter Hieronymus Bosch, through the perspective of present day thinkers and concepts
}

\author{
Tudor Jucan*
}

\begin{abstract}
We are Introduced of the subject matter of the article, the description of the chosen work by H Bosch, the triptych entitled: "The Garden of Earthly Delights" there is also a detailedphysical description of the work itself and of the concepts and ideas the Dutch painter plays with. We oversee the ambiguity of the interpretation normally given to the central panel mostly but create a dialogue with the narratives of the other two, thus the conceptual intention of the author is presented (the work itself by being in some's opinion a testimony to the uprising of the enlightenment (humanist) movements and the beginning of the Renaissance Era that took Europe and the World by storm... Although his images and ideas still echo in our present, by this reason we will employ the opinions of selected freethinkers that, in e strange way, engage the todays audience with the same concepts but somehow in a different paradigm: Paradise, Heaven, Heavenly Ecstasy, fear, acceptance etc. are just some of the forth mentioned subjects.The opinions will be set side by side to reveal the similarities or differences of Bosch's symbolism within present day concepts. The Illusion behind the concept of Heaven... or better said of the promised Garden; But also the necessity of heaving a wishful ideal to live up to... the concept of purposefulness, mindfulness switches the role of Paradise, and how to obtain it with, the lifetime goal for a happier life and a place within a peaceful inner self. In conclusion we can observe, the visionary aspect of the work itself and how the viewer can receivea new perspective on old subjects. By creating this conceptual bridge, we are all the closer to understanding how we are more similar with our forefathers, and how even from a 500-year-old painting we can still learn a thing or two about the present
\end{abstract}

Keywords: Garden, Paradise, Game-like quality, Humankind, knowledge, creator, meaningful, mindful, create, delights, earthly, heavenly.

* Cluj-Napoca University of Art and Design 
,Bosch is one of the very few painters who - he was indeed more than a painter! - who aquired a magic vision. He saw through the phenomenal world, rendered it transparent, and thus revield its pristine aspect,"l

Jheronimus van Aken, also known as Hieronymus Bosch, was a Dutch painter, one of the most notable representatives of the Early Netherlandish painting school. His work, generally oil on oak wood, mainly contains fantastic illustrations of religious concepts and narratives, especially macabre and nightmarish depictions of hell. His body of works, composed of more or less 27 pieces, conform neither to the post Middle Ages style of visual representations, nor to the Renaissance one,: he is, as H. Miller said, a visionary!

The trademark of his otherworldly representations of known art and religion themes are the fictive and grotesque characters that populate his panels. A man with animal like body, a knife between two ears, a"mur-maiden" holding a newborn riding a rat while being in a burrow are just a few of these small visual mysteries that keep our interest active, giving to all his works a feature that could be at any time a description of a Victorian curiosity cabinet, mystery beauty and amazement.

According to Dirk Bax, Bosch's paintings often represent visual translations of verbal metaphors and puns drawn from both biblical and folkloric sources. However, the conflict of interpretations that his works still elicit raises profound questions about the nature of "ambiguity" in the art of his period.

We will not take into discussion the whole character that is $\mathrm{H}$. Bosch and all of his works, neither vague generalities concerning it, but rather invite you to ponder on a simple question: "was he a mad painter, a Nostradamus-like figure or a misled soul in touch with a discourse from Heaven itself? Or could we see, behind the cloak, that he was actually a person that acknowledged many radical ideas of the time which in our era became, in some cases, " "the norm" ".

For this reason, I have chosen the subject of the garden (of paradise), masterfully represented by our painter in his most known work: The Garden of Eternal Delights. " "The Garden” in Bosch's vision, the one before the Flood, can be considered a projection that at any moment might become an "Earthly Paradise" , chocked by religious meanings and moral constraits imposed by its "zeitgeist". On closer inspection, the rhythm that the artist's work imposes by fully

\footnotetext{
${ }^{1}$ Stefan Fischer, Hieronymus Bosch, the complete works, Taschen 2013 (p. 98) Baldass 1959,( p. 234)
} 
sumberdging a subject matter... reveals to the non layman observer that morality is not a rigid term and, therefore, the image and the meaning it projects is, most probably, intentionally left ambiguous.

Even a a light objective reading of $\mathrm{H}$. Bosch's worksbrings to mind references to many of the great thinkers that preceded him: encapsulated within his works we can find a profoundly Humanist meaning (this being the case before it was cool!) ... And although we can argue on the true and harsh symbolistic thread of his imagistic discourse; but we cannot deny a subjective reality that regards the contemporary norm... Humanity needs only to lose its Fear of an external and higher punishment, thus regaining its primordial and righteous place within ," "God's Graces" ".

In the few works that are attributed to the artist we can discover traces that can transpire a "Game-like quality" " given to the life of man. What is curious within his full body of works, and especially in the triptych:" "The Garden of Eternal Delights" , is that somehow the folly of man is placed, atypically for the period, side by side with new or possibly old revised notions of what the values or perceptions of beauty, happiness and freedom could be. This statement is neither new nor shocking to those familiar with this subject; it might be wishful thinking... but, come to think of it, let us " "fall into temptation" ", let us have a moment of uninterrupted mindfulness directed towards a projection of... perhaps and endless possibilities...

There is an issue or a preference, we could say, for some of the subject matters of the art world, within the pre humanist era, starting with the Middle Ages and ending up somehow within the late 17th century, when there was an " "official censorship" " concerning the human body and its forbidden nakedness. Namely, more progressive artists would adopt religious subject matters that included the depiction of or at least the possibility of the naked or sensual human body being represented: " "Adam and Eve", "The Passions of Christ", "Susan and the Elders", "The Holly Virgin", "Scenes from the Old Testament", etc. These normal subjects were sometimes regarded as one of the fewest instances in which one may depart from the typical canonic representation of non-transgressive imagery, to a sometimes forbidden area of " "human studies" ", anatomical and physical at first but, later, even a social and psychological view of humanity. By these standards, it would be easy to state that $\mathrm{H}$. Bosch, leaving out all his corpus of works, and keeping just his "Garden" ", had - in some respects - a revolutionary perspective on these sensitive imageries.

There is, and has always been, a clash between our human nature and primordial yearnings and the social/cultural context and 
premise that, almost like a blacksmith forging iron into steel, set on a journey to reclaimed humanity's pure state, its essence, cast into history by the will to: tame, untame and re-tame the desire of man and its morality. To complete the start of this exposé on the slightly brave and in some way accepted heretical representation of religious and social dogma of the time, we must invoke the existentialist fundamental idea that freedom will appear in the moment one's limits are defined,: according to Sartre, among others, we have an inherent way or actually a need to be constrained by limits, so we can surpass them, finding purpose and meaning in the struggle it unleashes.

Let us familiarize ourselves with the image of the painting before going further with the proposed exposé.

"The Garden of Eternal Delights", painted most probably in 1503, on the occasion of the marriage of Henry III of Nassau Breda, was intended to serve as nuptial art, a sort of marital mirror (speculum nuptiorum, Vandenbroeck 1990, p.166, note 795), in other words a sort of a "how to" and "not to" in a successful marriage depicting the benefits and hazards that could await the freshly married couple. The work itself was constructed by the artist as a triptych having actually 4 images: The Creation of the World up to the Third Day plays across the two exterior shutters in the closed position, Paradise and the Creation of Eve are seen in the left inner wing, Humankind before the Flood is in the central panel, and the depiction of Hell is placed in the right inner wing. According to Baldass in his early analysis of the triptych, the works shows chronological and causal events of the world and humankind and the possibilities of being for the state of our souls, thereby representing a "didactic, moralizing,vanitas world picture" . By such notions we can understand that the painting was meant to instruct and entertain the viewer, encapsulating Bosch's duality.

Due to the type of problem raised here we will talk mostly about the central panel, due to its extreme ambiguity, and even though it could be said that all the works painted by Hieronymus have this feature, in this small section of his repertoire these issues are more visible.

The central panel is filed with a wealth of motifs being divided into a foreground scene, a middle distance one, and a spectacular background. Many of the elements repeat themselves. Naked men and women, fair or dark-skinned (representing possibly the descendants of Cain), birds, land, animals, also aquatic ones and a whole array of forms and structures, natural ones and seemingly artificial ones as well. Thematically, the scene represented here is based on the notion of Humanity before The Flood depicted in The Old Testament, an image encapsulating the trace of purity found in the left panel or Paradise, the 
so called folly of man and the imminent punishment that awaited him. In the author's time, the events described in The Bible were considered a historical fact, thusly there is the description of this exact moment.

The authors before Bosch in unison considered that the first age of man, which lasted from Adam to the Flood, was ruled by Lust. We might be tempted to associate some characters with the giants resulted from the union of Adam's kind with the corrupted descendants of Cain, or from the mixing between Angels and earthly women, yet these hypotheses can be neither proven, nor torn down, as these, and other meanings, are mostly arbitrary. Through the noise and abundance of sometimes shocking orgy images we see details like Adam, Eve and Noah in a cave, hiding from the mob-like dynamics of most of the characters. The man and women in the front ground seem not to live in caves anymore, some sheltering themselves in tent-like structures, an indication of their gradually evolving civilization that occurred after the Fall. The juxtaposition of man and woman, fruit and cavity, repeats itself several times in small groups engaged into what seems to be the exercitation of their free will, free from God's wrath and free from social norms; these, and the shabby or archaic architectural structures otherworldly in nature, are considered an indication of the "sin and debauchery" in which the son of man has fallen after the day in the first Garden.

Even though when looking at the image spread before our eyes we are confronted by the idea that the image has a certain "due date", an expiration term, the classic punishment after the crime, we are also struck by a sense of enjoyment and calmness, permitting our eyes to focus and leap from scene to scene, being amassed almost in a voyeuristic way, that we are quite unable to see sadness embracement or anger. We can plainly see that this is an earthly heaven, a representation derived from the notion of paradise as being an enclosed garden, but without a keeper. The symbiotic and playful representation of Humankind might be in some ways disturbing for Bosch's contemporaries but, in our times, at worst it could be judged as strange, but really strange in a playful bizarre way... the Harmony with Mother Nature is considered a mantra found today ubiquitously around the world.

Trees, shapes animals and invented beings are small signs or representations of ideas like marriage, sexuality, fertility, harmony this and the pure abundance of playful people and groups give this image the touch that is "needed" in a nuptial art piece.

While many of the pictorial motifs in the middle distance and background may not belong to the iconography of the Garden of Love, 
they can certainly be assigned to the thematic complex of sin and earthly love which are irreconcilably opposed. In the centre of the panel, a cavalcade of vices has formed a ring around a circular pond in which white and black women are bathing. The acrobatic riders galloping endlessly around this pool are "Fools of Venus, blinded and excited by their desire for love. These men riding around the pool, ultimately symbolize nothing less than the power to dominate women, which in the painter's equation is the inevitable correlative of male's sinfulness and folly. This patch from the painting representation of the dynamics of human Love can be seen as a warning for the viewer to consider that, even though the passion for love can be high, there is a constant danger to go "savage". A parallel was made by some that saw similarities between the action of the riders and old pagan cultures in which people would undergo ritualistic dances, incantations and processions combined with a high sexual tone to please or praise forgotten deities.

In the background, we conclude our view of this scene with a landscape of forest rivers structures and winged characters. The forests and the 4 rivers shown here are describing the "Paradise lost" ... its description can be found in The Old Testament; even though it has its physical form, it is somehow corrupted. We can plainly see that it is populated mostly by fantastic creatures, and this might be a result of humanity's fall from God's Graces,; in this way, he retains a part of his knowledge (gift) for us. An army of mermaids, a swimming unicorn are just some of the unearthly images that are played for us by our author. The architecture is more similar to the tower of Babel; they are flimsy despite their height. The shapes seem to evoke the feeling that this first age of man was like a house of cards, ambitious in its construction but faulted from the start, waiting for the right breeze or, in our case, wave, to tear them down.

The entire picture composes an image that invokes, at one's first glance, admiration and awe; we are transported into a realm of desire, temptation for fleshly pleasures, and this is not an unwanted feature, since it serves the proposed purpose of carrying the newlyweds into a state of permitted and condoned ecstasy.

The three panels are interlinked with meaning;, as Bosch tried, in this manner, to create a narrative guideline that can give deeper meaning to the viewer than a simple sermon or an interesting image. The motifs and images repeat themselves from one to the other, creating in this way a sort of mirror image of the central scene with the two on its flanks. The owl representing knowledge but also danger and wickedness, and also the unicorn which appears in Paradise, as well as all the other animals, fauna or flora, in high obedience to the three 
characters: Jesus, Adam and Eve. The central fountain and all the other structures are there placed organically in the composition. In the mirror image the image of the garden is one corrupted by Man. In Paradise we have stillness calm and obedience, in the central one we have chaos, man and beast are playing and copying each other's ways, people are grouping into actions to satisfy their pleasure. In this way, what once had been heavenly now became earthly, what once had been order now was chaos. But, as another will follow (the Flood), and another succeeded this (Genesis), we cannot be fully against chaos,: this state of turbulence was described at one point by philosopher Slavoj Zizek, as a necessary state of Revolution but an unnecessary mindset of perpetual revolt. The motion of the composition, even though it represents a parody of a central belief in a knowledgeable duality, gives the viewer, through its uncanny naturalness and visual flow, a sense of excitement and anticipation, but also a sense of calm and acceptance. Bosch employs parody as a tool during his creative process, in so far as he takes figures from the Paradise panel, places them into another and has them reflected in the third as a distortion.

If the image of the orgy-like world is one of ambivalence and, in some cases, careless freedom, the image of Man, Adam set in the lower down corner, represents the idea of Responsibility. We have freedom of will but we also have, as social beings, the responsibility to care and be compassionate to one another, and not only to mankind, but to all the other creatures of "The Divine" and to the creator Himself.

The idea of responsibility for one's actions is emblematic for this almost heretical religious painting. It takes the story line into a full circle; god, creation, laws, purposefulness, knowledge, beauty, lack of fear, freedom,; and, at this point, (being an enclosed space physically and mentally alike), freedom is misunderstood badly and, by losing responsibility, humankind (with the exception of Adam) loses its other virtues and integral traits, inviting Chaos to reign once more and reset the world to the position intended by God.

What follows in the storyline given to us by the artist is the representation of Hell, typical and representative for Bosch as a subject matter. But this should not be understood as in a deterministic narrative, but more as an allegory for the newlyweds: if you mistreat your family, father, mother, instincts, happiness, perspective and purpose in life...etc., you will suffer the consequences. And there... in this way I think that by far the visualization of Hell remains one of the "fetishes" of the Middle Ages society.

We could describe the grotesque images in the third image but we think it is best for our purpose here to understand its general 
meaning and to concentrate on how even Hell had the already obvious game-like features. There is no way of proving that Bosch's contemporaries would have perfectly understood the true meaning of his works, it is obvious he is on his own an eclectic artist and perhaps a forth thinker and a visionary. In any case, there always was a high interest for his otherworldly view of the world, his art giving a trend line of images and thinking from that age to the present day.

How do we perceive religion or its teachings? In the book: Religion for Atheists, the Swiss author and philosopher Alain De Botton, encourages us to reconsider how we read and think some aspects of belief and world view found in the religious spectrum. He brought up the dilemma regarding the origin of our moral compass for those of us who abandon religion In the 19th century people reasoned that Culture would strive and replace religion as the new sole owner of our morality. But, sadly, Culture, as it was to be, did not engage in a sense of teaching us how to live, how to deal with the subjective checkpoints of our life: live, love, dream, die, etc. The academic world left us cold so we always were in need of a narrative. Art for religions was crucial, it served a higher purpose, it is heartwarming to learn about the freeing of the arts from the yoke of the state or churches' exclusivity, but now we are confronted with art for art's sake, even though it had a way of using art as a propaganda tool, which meant that it was used as a didactical one. According to A de Botton, something was lost when Art separated from the masses, we slowly started to lose the link between great thinkers and great artists, so now, in contemporary times, everyone stands alone.

But, in fact, what is this mysterious Garden also known as Paradise? Actually, we will not talk in particular about a certain moment in one holy book or another, neither will we speak about the righteousness of any religion. We will start our exercise from the premise that the Holy Scriptures are an ancient codex for human psychology and its interactions as underlined by Jordan Peterson's concept exposed in his Biblical series:

"Humanity evolved a story-like structure through which to interpret the world! that's pretty damn interesting! it says something fundamental about stories and the storyteller."/" we have hemispheric specialization for the known and unknown: Order/Chaos). ${ }^{2}$

Bosch was perhaps a member of different directions of religious trend for his time, some more diverse and nonconformist than others. Paradise and Heaven, as we stated, were for him and his contemporaries real places... and in the end we will see that he was not 
far from the truth. The imagery he presented is so powerful that it makes itself relevant in our time also.

So how is this notion of an enclosed space, a walled oasis, relevant to the present time? How can walls present extreme happiness when in history they only create division and strife? Walls were as much a source of safety as a way to create tension and sorrow. From the Great IWall of China to the one that divided Berlin during the Cold war, we can see how real walls are compared with human individual and social boundaries.

Pope Francis spoke out against governments that build walls to keep out migrants, reiterating his calls for a compassionate approach to migration.

"Those who build walls will become prisoners of the walls they put up," the Pope said. "This is history" . Of course, this idea was not encouraged in the painter's time, walls were the way people dealt with the world and its problems, the world was known as static, limited and controlled; only a handful of pre-illuminists would create works to debate these "facts". The way Bosch creates his view of this earthly paradise struck us from the start as a daring way to see how one can represent sin without sinning, beauty and freedom without stepping on the moral teaching of the vigilant church. We can see that the image portrayed by one or another religion is not wrong, but merely does not help us detach from the stereotypical residual image of Heaven that we have formed in our head;: a luxurious place a place where all worries are gone, a place filled with all good things that does not tempt anyone to step out of line or to lead an unvirtuous existence. But it is wrong to continue to see Heaven or Paradise this way, many have died or committed acts of extreme cruelty towards their fellow man so they might be granted a place by the side of their ancestors that await them with open arms. For us to lead the best version of our lives, to be meaningful, and have purpose, Heaven must be impossible! Yes, there is a wickedness in affirming that such a place existed or will do again, and for heaven to work as a metaphor and to continue to enchant us with its idea, it has to be placed and kept in the realm of higher and fundamental concepts. It can be and represent our origins, with pride and suffering we obtained knowledge from its grasp. We were born there, we started to interact safely with the world... we came to think and feel for ourselves; does this sound familiar? It should, it is none other than a metaphor for the notion of family with God as a father figure and the tamed nature possibly the mother archetype.

But why impossible then? As a sum of things and features, this place can be placed with other abstract notions like: impossible, perfect, 
infinite. Let us ask ourselves how can it be perfect? If knowledge of his own existence was kept from Man, if the gaining of this knowledge was a capital sin., Man was in this sense just an automaton, a machine created to exist for a purpose in this place, a robot. Then can we speak of a revolt against his creator by its own creation, a theme all too present in all mediums of art and all eras.

Infinite is God and all its might. What is infinite I wonder? Zeno's paradox can simply start our mind thinking in a good direction; this ancient Greek philosopher tried to use methods to solve paradoxes that intrigued the mind of his contemporary world, so he embarked on a journey to see what infinity really is: in his theory, if one would shoot an arrow and by some chance (gravity, unknown to the ancients) it would not fall to the ground... would it fly forever or hit something? Let us say it would hit a wall, what now? Well, one would climb the wall and shoot it again... and so on and so on... for, you see, there are lots of infinities in this big one! What does this say about the Garden? That it was more like a limitation for Man to exist indefinitely. The idea that one can find true Paradise in its limitation is not a wrong or new one, but to limit others to your paradise easily you can detour one's consciousness into a living hell.

So a general Paradise does not exist, I suppose our painter knew this, when he painted The Garden of Eternal Delights. The garden in the central panel is a representation of an ideal earthly place, in my opinion, although for most of the art historians this is not the case, Through the way he set the stage and composed the colorful scene, Hieronymus Bosch dared to dream, to look at man, the beast of burden that became after the Fall a free beast... not threathening but free... free of consequence, free of fear, a rare moment at a time when beauty was not a burden on his sholders.

In conclusion, the notion of the garden (for me clearly the earthly one) is neither a goal nor a memory, it is a matrix to a life lived in a more mindful way in which you create a life of eternal delights.

\section{Bibliography:}

Stefan Fischer, Hieronymus Bosch, the complete works, Taschen 2013.

Baldass Hieronymus Bosch, Verlag Anton Schroll,1959.

The Psychological Significance of the Biblical Stories, Biblical Series II: Genesis 1: Chaos \& Order, Jordan B Peterson (Lecture May 23 at Isabel Bader Theatre, Toronto. 2017)

https://www.youtube.com/watch?v=hdrLQ7DpiWs\&list=PL22J3VaeABQD_IZs7 y60I3lUrrFTzkpat\&index $=2 \& a b \_c h a n n e l=J o r d a n B P e t e r s o n$ https://edition.cnn.com/2019/04/01/politics/pope-francis-wall/index.html 